\title{
Associative Factors for Birth Asphyxia at Queen Elizabeth Central Hospital-Malawi
}

\author{
Edith Tewesa', Ellen Chirwa $^{2}$, Maureen Daisy Majamanda², Alfred Maluwa², Angela Chimwaza ${ }^{2}$ \\ ${ }^{1}$ Queen Elizabeth Central Hospital, Blantyre, Malawi \\ ${ }^{2}$ University of Malawi-Kamuzu College of Nursing, Malawi \\ Email: etewesa@gmail.com, embweza@kcn.unima.mw, mdmajamanda@kcn.unima.mw, aomaluwa@kcn.unima.mw
}

How to cite this paper: Tewesa, E., Chirwa, E., Majamanda, M.D., Maluwa, A. and Chimwaza, A. (2017) Associative Factors for Birth Asphyxia at Queen Elizabeth Central Hospital-Malawi. Journal of Biosciences and Medicines, 5, 22-31.

https://doi.org/10.4236/jbm.2017.55003

Received: April 3, 2017

Accepted: May 23, 2017

Published: May 26, 2017

Copyright $\odot 2017$ by authors and Scientific Research Publishing Inc. This work is licensed under the Creative Commons Attribution International License (CC BY 4.0).

http://creativecommons.org/licenses/by/4.0/

\begin{abstract}
Background: Birth asphyxia is one of the major causes of neonatal deaths worldwide. Queen Elizabeth Central Hospital (QECH) neonatal ward records indicate that $36.5 \%$ of neonates admitted in the ward from April to September 2012 had birth asphyxia. This study was conducted to explore associative factors for birth asphyxia at QECH. Methodology: The study design was descriptive cross sectional that employed quantitative methods of data collection and analysis. Data sources were case notes of neonates and their mothers. Sample size was 87 neonates with birth asphyxia and 87 neonates admitted with conditions other than birth asphyxia as controls. Data were collected from November to December 2013. Statistical Package for Social Science (SPSS) version16.0 was used to analyze data. Results: Findings revealed that there were no maternal associative factors for birth asphyxia, however, foetal distress, prolonged first and second stage of labour were significant associative factors for birth asphyxia. Conclusion: Associative factors for birth asphyxia at QECH are Foetal distress, prolonged first and second stage of labour. These factors can be prevented if quality care is provided to women in labour through close monitoring of foetal heart, appropriate use of the partograph, prompt decision making and early interventions.
\end{abstract}

\section{Keywords}

Neonates, Birth Asphyxia, Risk Factors

\section{Introduction}

Birth asphyxia is defined as the neonate's failure to initiate and sustain breathing at birth [1]. It can be caused by events in the antepartum or intraparum period [2]. The World Health Organization (WHO) estimates that between four and nine million newborns develop birth asphyxia each year [3]. Out of these, an es- 
timated 1.2 million die and at least the same number develop severe complications such as epilepsy, cerebral palsy and developmental delay [3]. Globally, birth asphyxia is responsible for 42 million disability life adjusted years which is double that of diabetes and three quarters that of HIV/AIDS [4].

It is estimated that birth asphyxia is one of the major causes of neonatal deaths and contributes to nearly $40 \%$ of under-five mortality [5]. Malawi has made a steady progress in reducing under-five mortality from 244 to 71 deaths per 1000 live births between 1990 and 2012 [6]. Despite this progress, neonatal mortality rate is still high and is estimated to be 24 per 1000 live birth [7]. Queen Elizabeth Central Hospital $(\mathrm{QECH})$ neonatal ward records indicate that of the 1813 babies admitted in the ward from April to September 2012, 661 had birth asphyxia representing 36.5\%. From May to September 2012, there were 260 neonatal deaths of which 80 were due to birth asphyxia representing $30.8 \%$. This gives a picture that birth asphyxia is a big problem in Malawi. However, there is little information on associative factors for birth asphyxia in Malawi. This study was therefore conducted to explore the maternal, foetal and service associative factors for birth asphyxia at QECH. Examining associative factors for birth asphyxia will help to identify areas of improvement in delivery of midwifery care at QECH thereby preventing the occurrence of birth asphyxia and its complications.

\section{Methodology}

\subsection{Design}

This is a descriptive cross sectional study that employed quantitative methods of data collection and analysis to identify associative factors for birth asphyxia.

\subsection{Setting}

This study was conducted at QECH (Chatinkha neonatal unit) which is located in the southern region of Malawi. This hospital was chosen because it is a large referral hospital that receives complicated maternity cases from health centers and surrounding district hospitals, and has a large neonatal unit with a bed capacity of 64 and patient population per day of about 70 neonates.

\subsection{Methods}

Case notes for the mothers and neonates were used as data sources. Neonates admitted to the neonatal unit with birth asphyxia were recruited as cases and neonates admitted with other conditions other than birth asphyxia were recruited as controls. They were matched for birth weight and gestation age. The neonates were recruited within 24 hours of birth. Case notes of the neonates' mothers and neonates' admission forms were reviewed to identify the associative factors for birth asphyxia.

\subsection{Data Collection}

Data were collected from November to December 2013. Check lists were used to 
extract data from mothers' and neonates' case notes. The check list was developed from indicators on the partograph, Malawi Health Passport Woman Health Profile and the QECH neonatal admission form.

\subsection{Data Analysis}

Statistical Package for Social Science (SPSS) version 16.0 was used to analyze data. Frequencies and percentages were calculated for risk factors. Cross-tabulation was done between associative factors and the groups of neonates and Chi-square test was used at a test level of 0.05 to determine the associative factors for birth asphyxia.

\subsection{Study Population}

The population consisted of neonates who were admitted to the Chatinkha neonatal unit.

\subsection{Sampling}

All neonates $(\mathrm{N})$ admitted to the neonatal unit during the data collection period who met the inclusion criteria were recruited.

\subsection{Sample Size}

The sample size was 87 neonates who were admitted with birth asphyxia. An equal sample (87) of neonates admitted to the unit with conditions other than birth asphyxia served as a control group. The sample size was calculated using the Cochran (1963) Equation 1 which is $n_{0}=z^{2} p q / e^{2}$ and the sample size was reduced using the finite population correction for proportions Equation 3 which is $\mathrm{n}=\mathrm{n}_{0} / 1+\left(\mathrm{n}_{0}-1\right) / \mathrm{N}$.

\subsection{Inclusion/Exclusion Criteria}

Neonates with birth asphyxia and neonates with conditions other than birth asphyxia who were admitted to the neonatal unit at the time the study was conducted and whose parents had given consent were included. Diagnosis of birth asphyxia was considered in neonates with Apgar score of 6/10 or below or failure to cry at birth. The diagnosis was confirmed by checking the admission diagnosis. Neonates with congenital anomalies and those with birth weight less than 2000 grams were excluded as their condition could influence study outcomes due to their unique problems.

\subsection{Ethical Consideration}

The study was approved by College of Medicine Research and Ethics Committee (COMREC) in Malawi. A written consent was obtained from mothers of neonates with birth asphyxia as well as those whose neonates were admitted to the unit with conditions other than birth asphyxia. Verbal consent was obtained from the nurse/midwife in-charge of the neonatal unit and post natal ward before accessing the case notes. All other ethical issues such as avoiding harm and 
maintaining confidentiality were observed.

\section{Results}

\subsection{Clinical and Demographic Characteristics of Mothers of Neonates}

The age distributions of mothers in both groups were almost similar, there was no significant difference $(\mathrm{P}>0.05), 36.8 \%(\mathrm{n}=32)$ of mothers in the asphyxia group and $42.5 \%(\mathrm{n}=38)$ in the non-asphyxiated group were in the age category of 18 - 24 years. Levels of education for mothers in both groups were similar; there was no significant difference $(P \geq 0.05)$. Most of the mothers of both asphyxiated and non-asphyxiated neonates were multiparas $(47.1 \%, \mathrm{n}=41$ and $54 \%, \mathrm{n}=47$ ) respectively Table 1 .

Table 1. Clinical and demographic characteristics of mothers.

\begin{tabular}{cccc}
\hline Characteristic & $\begin{array}{c}\text { Asphyxia } \\
\mathbf{n}(\%)\end{array}$ & $\begin{array}{c}\text { Non asphyxia } \\
\mathbf{n}(\%)\end{array}$ & p value \\
\hline Age (years) & & & \\
less than 18 & $13(14.9)$ & $13(14.9)$ & $\mathbf{0 . 8 6 7}$ \\
$18-24$ & $32(36.8)$ & $37(42.5)$ & \\
$25-34$ & $38(43.7)$ & $34(39.1)$ & $\mathbf{0 . 6 6 3}$ \\
$>/=35$ & $4(4.6)$ & $2(2.3)$ & \\
Education & $5(5.7)$ & $62(71.2)$ & \\
never been to school & $59(67.8)$ & $20(23)$ & \\
primary & $21(24.2)$ & $3(3.5)$ & \\
secondary & $2(2.3)$ & $32(36.8)$ & \\
tertiary & $37(42.5)$ & $47(54)$ & \\
Parity & $41(47.1)$ & $8(9.2)$ & \\
primpara & $9(10.2)$ & & \\
multipara & & & \\
grand multipara & & & \\
& & & \\
\hline
\end{tabular}

Table 2. Clinical and demographic characteristics of the neonates.

\begin{tabular}{ccc}
\hline Characteristic & $\begin{array}{c}\text { Asphyxia } \\
\mathbf{n}(\%)\end{array}$ & $\begin{array}{c}\text { Non asphyxia } \\
\mathbf{n}(\%)\end{array}$ \\
\hline Place of delivery & $66(75.8)$ & $65(74.7)$ \\
QECH & $19(21.8)$ & $20(23.0)$ \\
Health Centre & $1(1.2)$ & $0(0.0)$ \\
Home & $1(1.2)$ & $2(2.3)$ \\
On the way & & \\
Mode of delivery & $47(54.0)$ & $42(48.3)$ \\
SVD & $34(39.1)$ & $38(43.7)$ \\
LUCS & $1(1.2)$ & $3(3.4)$ \\
V/ Extraction & $5(5.7)$ & $4(4.6)$ \\
Breech & & $0(0.0)$ \\
Birth weight & $0(0.0)$ & $4(4.6)$ \\
$1000-2000$ & $5(5.7)$ & $72(82.8)$ \\
$>2000-<2500$ & $75(86.3)$ & $11(12.6)$ \\
$2500-3500$ & $7(8.0)$ & \\
$>3500$ & &
\end{tabular}




\subsection{Clinical and Demographic Characteristics of Neonates}

Place of birth for the majority of neonates in both groups $(75.8 \%, \mathrm{n}=66)$ for the asphyxiated neonates and 74.7\% $(\mathrm{n}=65)$ for the non-asphyxiated was QECH (P $\geq 0.05$ ). The major mode of delivery in both groups was Spontaneous Vertex Delivery (SVD) which was 54\% $(\mathrm{n}=47)$ in asphyxiated neonates and $48.3 \%(\mathrm{n}=$ $42)$ in non-asphyxiated neonates ( $P \geq 0.05)$; followed by Caesarean Section. Majority of neonates in the asphyxia group $(92 \%, \mathrm{n}=80)$ were born at term gestation (37 - 40 weeks). Similarly, $93.1 \%(\mathrm{n}=81)$ of the non-asphyxiated neonates were born at term gestation $(\mathrm{P} \geq 0.05)$ Table 2 .

\subsection{Maternal Associative Factors}

In this context, maternal factors refer to pre-existing conditions in the mother. Chi-square tests were calculated between the asphyxia and non-asphyxia group on each factor to determine the associative factors for birth asphyxia. No significant differences $(P>0.05)$ was identified between the groups of neonates on the following factors; age of mothers, level of education and parity suggesting that these factors were not risk factors for birth asphyxia.

None of the mothers in either group had eclampsia, diabetes, or epilepsy. Therefore these factors could not be assessed. However, there were no significant differences $(P>0.05)$ between the mothers in the asphyxia group and non-asphyxia group on the following conditions; pre-eclampsia, anaemia, pyretic diseases, prolonged rupture of membranes, HIV positive sero status, and Cephalo Pelvic Disproportion (CPD), suggesting that these were not associative factors for birth asphyxia.

None of the mothers in either group received Magnesium Sulphate, or Diazepam, and therefore the relationship between administration of these drugs and birth asphyxia could not be assessed. Never the less, there were no significant differences $(P>0.05)$ between mothers of asphyxiated neonates and non-asphyxiated neonates on the following medications; Antihypertensives, ART, Antibiotics, Pethidine, Oxytocin and Misoprostol suggesting that these medications were not associative factors for birth asphyxia.

\subsection{Foetal Risk Factors}

Significant differences $(\mathrm{P}<0.05)$ were noted between the asphyxia and non-asphyxia groups on foetal distress suggesting that foetal distress was an associative factor for birth asphyxia. However, no significant differences $(\mathrm{P}>0.05)$, were observed between the two groups on birth weight, gestation age, malpresentation and multiple gestation, suggesting that these were not associative factors for birth asphyxia.

\subsection{Service Risk Factors}

In this context, service refers to the way care is provided in the hospital. Significant differences $(\mathrm{P}<0.05)$ were identified between the groups of neonates on the following factors: prolonged first stage of labour and prolonged second stage of 
labour, suggesting that these were significant associative factors for birth asphyxia. However, no significant differences $(\mathrm{P}>0.05)$ were observed on the following factors; antenatal check-up, inconsistent monitoring of first stage of labour, no monitoring of first stage of labour, and mode of delivery suggesting that these were not associative factors for birth asphyxia.

Results of this study show that there were no maternal associative factors for birth asphyxia. Foetal distress was the only foetal associative factor identified. Service associative factors identified were prolonged first stage of labour and prolonged second stage of labour.

\section{Discussion}

\subsection{Mothers' Clinical and Demographic Characteristics}

Findings in this study showed that maternal age was not an associative factor for birth asphyxia. This finding suggests that pregnancy and labour in all age groups should be effectively managed as maternal age cannot predict the occurrence of birth asphyxia. This finding is similar with Nayeri et al. [8] in Iran and Lee et al. [1] in Southern Nepal. On the other hand, Lamminpaa et al. [9] in Finland and Berglund et al. [10] in Sweden found that the risk of birth asphyxia increased with advanced maternal age. The difference in the finding might be attributed to the differences in sample size and the setting in which the studies were conducted. Maternal age was included as the potential associative factor for birth asphyxia in this study because young and advanced maternal ages are associated with difficult labour.

Findings further showed that level of education was not an associative factor for birth asphyxia. Although the level of education was not a significant associative factor for birth asphyxia in this study, it was noted that as maternal education increased from primary to secondary and tertiary, the frequency of birth asphyxia decreased. Contrary to the findings in this study, Lee et al. [1] in Nepal and Odd et al. [11] in Sweden found that the risk for birth asphyxia decreased significantly with increasing maternal education. The difference in the finding could be attributed to differences in sample sizes. This study recruited 174 neonates, the Nepal study recruited 23,662 infants, and the Sweden study recruited 183,637 neonates. Maternal education was included as potential associative factor for birth asphyxia because good educational back ground is also associated with appropriate health seeking behavior.

Parity was not an associative factor for birth asphyxia. Similarly Nayeri et al. [8] in Iran found that primiparity was not a risk factor for birth asphyxia. On the other hand Foumane et al. [12] in Cameroon found that first delivery increased the risk of birth asphyxia. In addition, these researchers also found that primiparity was significantly associated with prolonged second stage of labour which was a significant exposure to clinical birth asphyxia and newborn death.

\subsection{Clinical and Demographic Characteristics of the Neonates}

The following were not associative factors for birth asphyxia; place of delivery, 
mode of delivery, birth weight, and gestation age. This is consistent with results of previous studies done in Sweden and Cameroon [12] [13]. Although not statistically significant, findings showed that the majority of asphyxiated neonates were delivered through SVD. This suggests that there might be delay in decision making on the mode of delivery which might complicate the outcome of labour. This is in agreement with Sepeku and Kohi [14] in Tanzania who found that the majority of asphyxiated neonates were delivered by SVD. Contrary to the findings of this study, Majeed et al. [15] in India; Rachatapantanakorn et al. [16] in Thailand and Berglund et al. [10] in Sweden, found that prematurity and post maturity were risk factors for low Apgar scores. The difference in the finding could be attributed to the fact that the majority of neonates in this study were born at term gestation.

\subsection{Maternal Associative Factors}

Findings of the study revealed that the following maternal conditions were not significant associative factors for birth asphyxia: anaemia, pyretic diseases, prolonged rupture of membranes (PROM), Antepartum Haemorrhage (APH), preeclampsia, HIV sero positive status and Cephalopelvic disproportion (CPD). In addition none of the mothers in both groups had eclampsia, diabetes or epilepsy. These conditions were therefore not assessed. Results of this study therefore suggest that prediction of birth asphyxia using maternal conditions is challenging as birth asphyxia can occur regardless of preexisting maternal diseases. Midwives therefore should be vigilant at every birth to be able to assist effectively neonates who fail to breathe at birth. This finding is consistent with results of studies done in Nigeria, Sweden and Iran [8] [13] [17]. Contrary, studies done in Cameroon, Uganda, India and Thailand [15] [18] [19] [20] suggested that maternal conditions were risk factors for birth asphyxia.

Findings of the study further showed that the following medications which were given to mothers of neonates antenatally or during labour were not significant associative factors for birth asphyxia: antihypertensives, ART, antibiotics, pethidine, oxytocin and misoprostol. Contrary to this finding, Pitsawong and Panichkul [2] in Thailand, Khunpradit [20] in Thailand, Kaye [19] in Uganda, and Shireen et al. [21] in Bangladesh found that pethidine and oxytocin were independent risk factors for birth asphyxia. The difference in the finding could be attributed to the difference in sample size. Although medications given to mothers were not significant associative factors for birth asphyxia, mothers on medication should be closely monitored in labour for early detection of complications to improve the pregnancy outcome.

\subsection{Foetal Associative Factors}

Foetal distress was the only significant associative factor for birth asphyxia. The finding suggests that foetal distress predisposes neonates to birth asphyxia. Midwives and clinicians should therefore be alert to identify and manage foetal distress efficiently. They should also watch out for predisposing factors to foetal 
distress so that they are prevented. The study further indicated that malpresentation, and multiple gestations were not significant associative factors for birth asphyxia. Although malpresentation and multiple gestations were not significant associative factors for birth asphyxia, they might be predisposing factors to foetal distress. Therefore mothers should be closely monitored antenatally and during labour to prevent foetal distress. This finding partially agrees with findings reported by Khunpradit [20] in Thailand, indicating that foetal distress was a risk factor for birth asphyxia. Pitsawong and Panichkul [2] in Thailand also found that twin gestation was not a risk factor for birth asphyxia. On the contrary, Khunpradit [20] and Pitsawong and Panichkul [2] both in Thailand, found that malpresentation were also risk factors for birth asphyxia.

\subsection{Service Associative Factors}

Results showed that prolonged first stage of labour and prolonged second stage of labour were significant associative factors for birth asphyxia. Similarly, Berglund et al. [10] in Sweden found that the most common events of malpractice in connection with delivery were neglecting to supervise foetal wellbeing and neglecting signs of foetal asphyxia. In this study, if partographs were used effectively to monitor labour, prolonged labour would be avoided thereby reducing possibility for birth asphyxia. Similarly, Chiabi et al. [18] in Cameroon; Foumane et al. [12] in Cameroon and Kumar et al. [22] in India; found that prolonged labour was a risk factor for birth asphyxia.

Antenatal follow up was not a associative factor for birth asphyxia. Similarly, Nayeri et al. [8] in Iran found that incomplete perinatal care was not a risk for birth asphyxia. Although not significant risk factor, it is an important factor because antenatal follow up helps in early detection of problems and prompt management hence decreasing chances of problems to the neonate during or after delivery [22]. This finding is however inconsistent with what Majeed et al. [15] in India and Berglund et al. [10] in Sweden found. They identified that lack of antenatal care was associated with birth asphyxia.

Results further showed that induced labour was not a significant associative factor for birth asphyxia. Similarly, Dongol et al. [23] found that birth asphyxia was less commonly seen in mothers whose labour was induced $(27.4 \%, \mathrm{n}=28)$ than those whose labour was not induced $(72.5 \%, \mathrm{n}=74)$. Contrary, Sepeku and Kohi [14] in Tanzania and Berglund et al. [10] in Sweden found that induced labour was a significant risk factor for birth asphyxia. Although in this study induced labour was found to be an insignificant associative factor for birth asphyxia, women on induction of labour require close monitoring to achieve good outcome.

\section{Conclusion}

Birth asphyxia is one of the leading causes of neonatal deaths. Neonates who suffer birth asphyxia can have long-term neurological complications which might affect their quality of life. Findings of this study have shown that associa- 
tive factors for birth asphyxia at QECH are prolonged first stage of labour, prolonged second stage of labour and foetal distress. These factors can be prevented if women in labour are effectively monitored through appropriate use of the partograph and prompt decisions and actions are taken. As a result, birth asphyxia and its consequences could be prevented. Therefore, midwives and clinicians in labour ward should reinforce effective monitoring of women in labour. Supportive supervision by midwifery leaders and obstetricians should be intensified to improve quality of care rendered to women in labour. There is also need to strictly monitor foetal condition in women in labour for early detection and prompt management of foetal distress.

\section{Limitation}

The study was conducted at one facility and the sample size was small. Therefore, the results may not be generalized to the whole country.

\section{Acknowledgements}

All authors for their valuable contributions. The study was conducted as part of the Master of Science degree in midwifery at the University of Malawi, Kamuzu College of Nursing with a scholarship from global Rolling Continuation Channel.

\section{References}

[1] Lee, A., Mullany, L.C., Tielsch, J.M., Katz, J., Khatry, S.K., LeClerq, S.C. and Darmstadt, G.L. (2008) Risk Factors for Neonatal Mortality Due to Birth Asphyxia in Southern Nepal. Pediatrics, 121, e1381-e1390.

[2] Pitsawong, C. and Panichkul, P. (2011) Risk Factors Associated with Birth Asphyxia in Phramongkutklao Hospital. Thai Journal of Obstetrics \& Gynaecology, 19, 165 171.

[3] Haider, B.A. and Bhutta, Z.A. (2006) Birth Asphyxia in Developing Countries: Current Status and Public Health Implications. Current Problems Peadiatric Adolescent Health Care, 36, 178-188. https://doi.org/10.1016/j.cppeds.2005.11.002

[4] Robertson, N.J., Hagmann, C.F., Acolet, D., Allen, E., Nyombi, N., Elbourne, D. and Cowan, F. (2011) Pilot Randomized Trial of Therapeutic Hypothermia with Serial Cranial Ultrasound and 18 - 22 Month Follow Up for Neonatal Encephalopathy in Low Resource Hospital Setting in Uganda: Study Protocol. Trials, 12, 138. https://doi.org/10.1186/1745-6215-12-138

[5] WHO (2012) Newborns: Reducing mortality. WHO Fact Sheet, 333.

[6] World Bank (2014) Achieving MDGS 4 \& 5: Malawis's Progress on Maternal and Child Health: Health, Nutrition and Population Global Practice Knowledge Brief. World Bank Group.

http://documents.worldbank.org/curated/en/2014/08/20370508/achieving-mdgs-45-malawis-progress-maternal-child-health

[7] UNICEF (2013) Levels and Trends in Child Mortality. www.who.int/maternal_child_adolescent/epidemiology/profile/neonatal_child/mwi pdf

[8] Nayeri, F., Shariat, M., Dalili, H., Adam, L.B., Mehrjerdi, F.Z. and Shakeri, A. (2012) Perinatal Risk Factors for Neonatal Asphyxia in Vali-e-Asr Hospital, Tehran-Iran. 
Iranian Journal of Reproductive Medicine, 10, 137-140.

[9] Lamminpaa, R. Vehvilainen-Julkunen, K., Gissler, M. and Heinonen, S. (2012) Preeclampsia Complicated by Advanced Maternal Age: A Registry-Based Study on Primiparous Women in Finland 1997-2008. BioMed Central Pregnancy Childbirth, 12, 47. https://doi.org/10.1186/1471-2393-12-47

[10] Berglund, S., Pettersson, H., Cnattingius, S. and Grunewald, C. (2010) How Often Is Low Apgar Score the Result of Substandard Care during Labour? British Journal of Obstetrics and Gynaecology, 117, 968-978. https://doi.org/10.1111/j.1471-0528.2010.02565.x

[11] Odd, D., Lewis, G., Gunnel, D. and Rasmussen, F. (2014) Risk of Low Apgar Scores and Socio-Economic Status over a 30-Year Period. Journal of Maternal-Foetal and Neonatal Medicine, 2, 603-607. https://doi.org/10.3109/14767058.2013.833903

[12] Foumane, P., Nkomon, G., Mboudou, E.T., Sama, J.D., Nguefack, S. and Moifo, B. (2013) Risk Factors of Clinical Birth Asphyxia and Subsequent Newborn Death Following Nuchal Cord in a Low-Resource Setting. Open Journal of Obstetrics and Gynecology, 3, 642-647. https://doi.org/10.4236/ojog.2013.39117

[13] Milsom, I., Ladfors, L., Thiringer, K., Niklasson, A., Odeback, A. and Thornberg, E. (2002) Influence of Maternal, Obstetric \& Foetal Risk Factors on the Prevalence of Birth Asphyxia at Term in a Swedish Urban Population. Acta Obstetrica et Gynecologica Scandinavica, 81, 909-917. https://doi.org/10.1034/j.1600-0412.2002.811003.x

[14] Sepeku, A. and Kohi, T.W. (2011) Treatment Outcome of Neonatal Asphyxia at a National Hospital in Dar es Salaam, Tanzania. Africa Journal of Nursing \& Midwifery, 13, 43-56.

[15] Majeed, R., Memon, Y., Majeed, F., Shaikh, N.P. and Rajar, U.D. (2007) Risk Factors of Birth Asphyxia. Journal of Ayub Medical College Abbottabad, 19,, 67-71.

[16] Rachatapantanakorn, O., Tongkumchum, P. and Chaisuksant, Y. (2005) Factors Associated with Birth Asphyxia in Pattani Hospital, Thailand. Songkla Medical Journal, 23, 17-27.

[17] West, B.A. and Opara, P.I. (2013) Perinatal Asphyxia in a Specialist Hospital in Port Harcourt, Nigeria. Nigerian Journal of Paediatrics, 40, 206-210.

[18] Chiabi, A., Nguefack, S., Mah, E., Nodem, S., Mbuagbaw, L., Mbonda, E. and Tchokoteu, P. (2013) Risk Factors for Birth Asphyxia in Urban Health Facility in Cameroon. Iranian Journal of Child Neurology, 7, 46-54.

[19] Kaye, D. (2003) Antenatal and Intrapartum Risk Factors for Birth Asphyxia among Emergency Obstetric Referrals in Mulago Hospital, Kampala, Uganda. East African Medical Journal, 80, 140-143.

[20] Khunpradit, S. (2004) Risk Factors for Birth Asphyxia: A Case Control Study. Journal of the Medical Association of Thailand, 87, s264-s265.

[21] Shireen, N., Nahar, N. and Mollar, A.H. (2009) Risk Factors and Short Term Outcome of Birth Asphyxiated Babies in Dhakar Medical College Hospital. Bangladesh Journal of Child Health, 33, 83-89.

[22] Kumar, S., Nizamani, M.A. and Memon, S. (2014) Risk Factors in Birth Asphyxia at Liaquat University Hospital Hyderabad. Medical Channel, 20, 35-38.

[23] Dongol, S., Singh, J., Shrestha, S. and Shakya, A. (2010) Clinical Profile of Birth Asphyxia in Dhulikhel Hospital: A Retrospective Study. Journal of Nepal Paediatric Society, 30, 141-146. https://doi.org/10.3126/jnps.v30i3.3916 
Submit or recommend next manuscript to SCIRP and we will provide best service for you:

Accepting pre-submission inquiries through Email, Facebook, LinkedIn, Twitter, etc. A wide selection of journals (inclusive of 9 subjects, more than 200 journals)

Providing 24-hour high-quality service

User-friendly online submission system

Fair and swift peer-review system

Efficient typesetting and proofreading procedure

Display of the result of downloads and visits, as well as the number of cited articles Maximum dissemination of your research work

Submit your manuscript at: http://papersubmission.scirp.org/

Or contact jbm@scirp.org 